\title{
Pyroelectric properties of lead-barium titanate and lead-strontium titanate
}

\author{
V M JAMADAR, T A PATIL* and S H CHAVAN** \\ Department of Physics. Dattajirao Kadam Mahavidyalay, Ichalkaranji 416 115, India \\ *Vivekanand College. Kolhapur 416002, India \\ **Department of Physics, Shivaji University, Kolhapur 416004 , India \\ MS received 1 June 1987; revised 21 August 1987
}

\begin{abstract}
Pyroelectric properties of poled solid solutions of lead-barium titanate and leadstrontium titanate have been investigated in the temperature range covering their transition points. The values of pyroelectric current and coefficients of $\left(\mathrm{Pb}_{x}-\mathrm{Ba}_{1}-\mathrm{TiO}_{3}\right.$ and $\left(\mathrm{Pb}_{x}-\mathrm{Sr}_{1-x}\right) \mathrm{TiO}_{3}(x=0.8-0.5)$ show a sharp peak at the Curie temperature. It is observed that these values change with $\mathrm{Ba}$ or $\mathrm{Sr}$ concentration in the respective solid solutions.
\end{abstract}

Keywords. Titanate solid solutions; pyroelectric behaviour; phase transition.

\section{Introduction}

The primary pyroelectricity is defined as the change of polarization of a dielectric with the temperature after eliminating polarization effects produced by thermal strains which accompany the temperature changes according to the terminology introduced by Cady (1946). There is, in general, some contribution to the polarization change with temperature due to the thermal expansion or contraction of the dielectric. Pearls et $a l(1958)$ and Tawfik (1969) have reported that the secondary effect in $\mathrm{BaTiO}_{3}$ is small. Primary pyroelectricity in ferroelectric ceramics can arise from two factors: (i) the primary effect of aligned domains and (ii) switching of domains by $180^{\prime}$.

The pyroelectric effect in barium titanate ceramic was studied by Lang et al (1969). A dynamic method has been devised by Chynoweth (1956) to measure pyroelectric effect in barium titanate. Temperature dependence of pyroelectric current in potassium nitrate has been studied by Sawada et al (1961). The pyroelectric current measurements and effects of poling and of light illumination upon pyroelectric current in SbSI were found by Imai et al (1966). A direct method for measuring the pyroelectric coefficients and application to a nsec response time detector $\left(\mathrm{Sr}_{x}-\mathrm{Ba}_{1-x}\right) \mathrm{Nb}_{2} \mathrm{O}_{6}$ was described by Byer and Roundy (1972). Pyroelectric properties were studied by Vasileva (1977) in triglycine sulphate and by Tawfik (1974) in the polarized specimen of sodium acetylacetonate. Dielectric and pyroelectric properties of triglycine sulphate polystyrene composite were studied by Mansingh and Sreenivas (1983). Similar properties were studied by Mathur et al (1981) in TGS, TGFS etc and by Yuhan (1984) in ferroelectric single crystal series $\left(\mathrm{K}_{x}-\mathrm{Na}_{1-x}\right)_{0 \cdot 4}$ $\left(\mathrm{Sr}_{y}-\mathrm{Ba}_{1-y}\right)_{0.8} \mathrm{Nb}_{2} \mathrm{O}_{6}$. Pyroelectric materials have also been reviewed recently by Srinivasan (1984).

The present investigation aims to report the variation of pyroclectric current and coefficients with temperature in the poled solid solutions of $\left(\mathrm{Pb}_{x}-\mathrm{Ba}_{1-x}\right) \mathrm{TiO}_{3}$ and

**Address for communication 
$\left(\mathrm{Pb}_{x}-\mathrm{Sr}_{1-x}\right) \mathrm{TiO}_{3}$. These solid solutions, being ferroelectric materials, exhibit interesting pyroelectric properties and have practical applications as pyroelectric detectors which are of special interest.

\section{Experimental}

Lead titanate ceramics were prepared from a mixture of lead carbonate and titanium dioxide with 1:1 molar proportions and heated in platinum crucible in globar furnace upto $1200^{\circ} \mathrm{C}$ for $4 \mathrm{hr}$ by the method reported by Sawada et al (1950). Similarly $\mathrm{BaTiO}_{3}$ and $\mathrm{SrTiO}_{3}$ ceramics were prepared.

Solid solutions $\left(\mathrm{Pb}_{x}-\mathrm{Ba}_{1-x}\right) \mathrm{TiO}_{3}$ were prepared from a mixture of $\mathrm{PbTiO}_{3}$ and $\mathrm{BaTiO}_{3}$ having molar proportions of $(x=0.8-0.5)$ and heated in globar furnace at $1200^{\circ} \mathrm{C}$ for $4 \mathrm{hr}$ in a platinum crucible. The solid solutions $\left(\mathrm{Pb}_{x}-\mathrm{Sr}_{1-x}\right) \mathrm{TiO}_{3}$ $(x=0.8-0.5)$ were similarly prepared.

The X-ray powder diffractions of our samples confirm that homogeneous solid solutions have been formed. The pellets of these solid solutions having thickness of about $1 \mathrm{~mm}$ and diameter $1 \mathrm{~cm}$ were prepared under a pressure of 5 tonnes by using a hydraulic machine. The test samples were made by sintering these pellets at $750^{\circ} \mathrm{C}$. The two end-faces of these test samples were made conducting by applying silver paint and were placed in the sample holder fabricated in our laboratory.

The experimental set-up consists of a furnace, electronically regulated power supply to provide d.c. electric field, a digital d.c. micro-voltmeter (VMV 15), a picoammeter adaptor for VMV 15 and a digital multimeter. The test sample was polarized for $10 \mathrm{~min}$ at room temperature by a constant d.c. electric field of $1 \mathrm{kV} / \mathrm{cm}$. To eliminate the current due to the space charge, the test sample electrodes were shortcircuited for $30 \mathrm{~min}$ before the pyroelectric measurements. This poled sample was slowly heated in a furnace and the pyroelectric current was measured with a digital d.c. micro-voitmeter (VMV 15) connected to the pico-ammeter adaptor at various temperatures and the corresponding time was also noted for calculating the rate of heating. The heating rate was determined from the graph of temperature against time and was found to be nearly $3^{\circ} \mathrm{C} / \mathrm{min}$. The pyroelectric coefficients were calculated by the direct method suggested by Byer and Roundy (1972) and Mansingh et al (1983), which is more straightforward than the dynamic method.

\section{Results and discussion}

The results of the measurements of the pyroelectric current and coefficients in solid solutions of $\left(\mathrm{Pb}_{x}-\mathrm{Ba}_{1-x}\right) \mathrm{TiO}_{3}$ and $\left(\mathrm{Pb}_{x}-\mathrm{Sr}_{1-x}\right) \mathrm{TiO}_{3}$ obey the equation given by Chynoweth (1956)

$$
i=A\left[\left(\mathrm{~d} P_{s} / \mathrm{d} T\right)(\mathrm{d} T / \mathrm{d} t)\right] .
$$

where $i$ is the pyroelectric current, $P_{s}$ the spontaneous polarization, $(\mathrm{d} T / \mathrm{d} t)$ the rate of heating, $A$ the area of the ceramic material and $\left(\mathrm{d} P_{\mathrm{s}} / \mathrm{d} T\right)$ the pyroelectric coefficient.

The pyroelectric current response for ferroclectric solid solutions of $\left(\mathrm{Pb}_{x}-\mathrm{Ba}_{1-x}\right) \mathrm{TiO}_{3}$ and $\left(\mathrm{Pb}_{x}-\mathrm{Sr}_{1-x}\right) \mathrm{TiO}_{3}$ on heating at the rate $\sim 3 \mathrm{C} / \mathrm{min}$ are shown in tigures 1 and 2. The pyroelectric current produced in solid solutions 


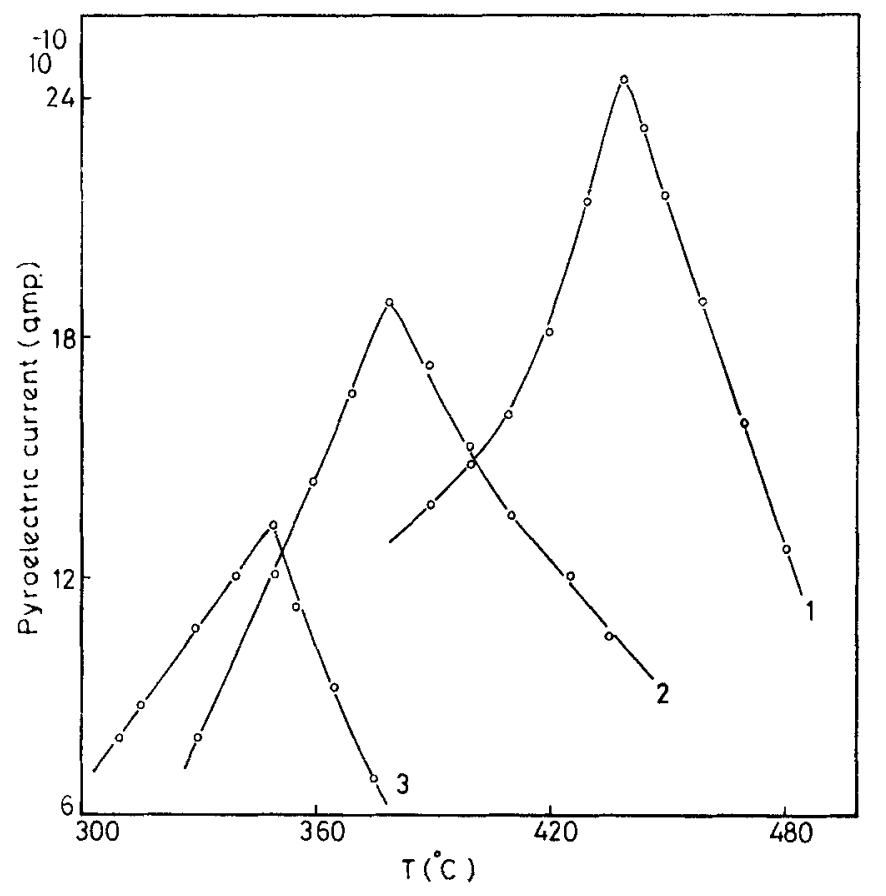

Higure 1. Temperature dependence of the pyroelectric current in poled sample 1. $\left(\mathrm{Pb}_{0.8}-\mathrm{Ba}_{0,2}\right) \mathrm{TiO}_{3}$, 2. $\left(\mathrm{Pb}_{0.6}-\mathrm{Ba}_{0.4}\right) \mathrm{TiO}_{3}$ and $\left(\mathrm{Pb}_{05}-\mathrm{Ba}_{5}\right) \mathrm{TiO}_{3}$.

(figures 1 and 2) arose as a consequence of the change in polarization of a ceramic when it underwent a variation in its temperature.

From figures 1 and 2 it is clear that the pyroelectric current shows a peak at 440 , 380 and $350^{\circ} \mathrm{C}$ for different molar proportions of $\left(\mathrm{Pb}_{x}-\mathrm{Ba}_{1-x}\right) \mathrm{TiO}_{3}$ and at 340,200 and $125^{\circ} \mathrm{C}$ for different molar proportions of $\left(\mathrm{Pb}_{x}-\mathrm{Ba}_{1-x}\right) \mathrm{TiO}_{3}$. The above temperatures indicate Curie temperatures of the respective solid solutions which are consistent with the Curie temperatures determined by the hysteresis loop method and the dielectric constant measurements. These solid solutions belong to the polar class below their Curie temperatures while above they are non-polar.

Table 1 summarizes the observations on the pyroelectric current and pyroelectric coefficients at the Curie temperatures of the solid solutions.

Table 1 reveals that the pyroelectric current and the coefficients increase as the proportion of $\mathrm{PbTiO}_{3}$ increases in the respective solid solutions of $\left(\mathrm{Pb}_{x}-\mathrm{Ba}_{1-x}\right) \mathrm{TiO}_{3}$ and $\left(\mathrm{Pb}_{x}-\mathrm{Sr}_{1-x}\right) \mathrm{TiO}_{3}$.

\section{Conclusions}

It seems that 440,380 and $350^{\circ} \mathrm{C}$ are the Curie temperatures for molar proportions of $\left(\mathrm{Pb}_{x}-\mathrm{Ba}_{1-x}\right) \mathrm{TiO}_{3}$ with $(x=0.8,0.6$ and 0.5$)$ and for different molar proportions of $\left(\mathrm{Pb}_{x}-\mathrm{Sr}_{1-x}\right) \mathrm{TiO}_{3} ; 340,200$ and $125^{\circ} \mathrm{C}$ are the Curie temperatures. Pyruelectric current and coefficients increase with the proportion of $\mathrm{PbTiO}_{3}$ in solid solution. 


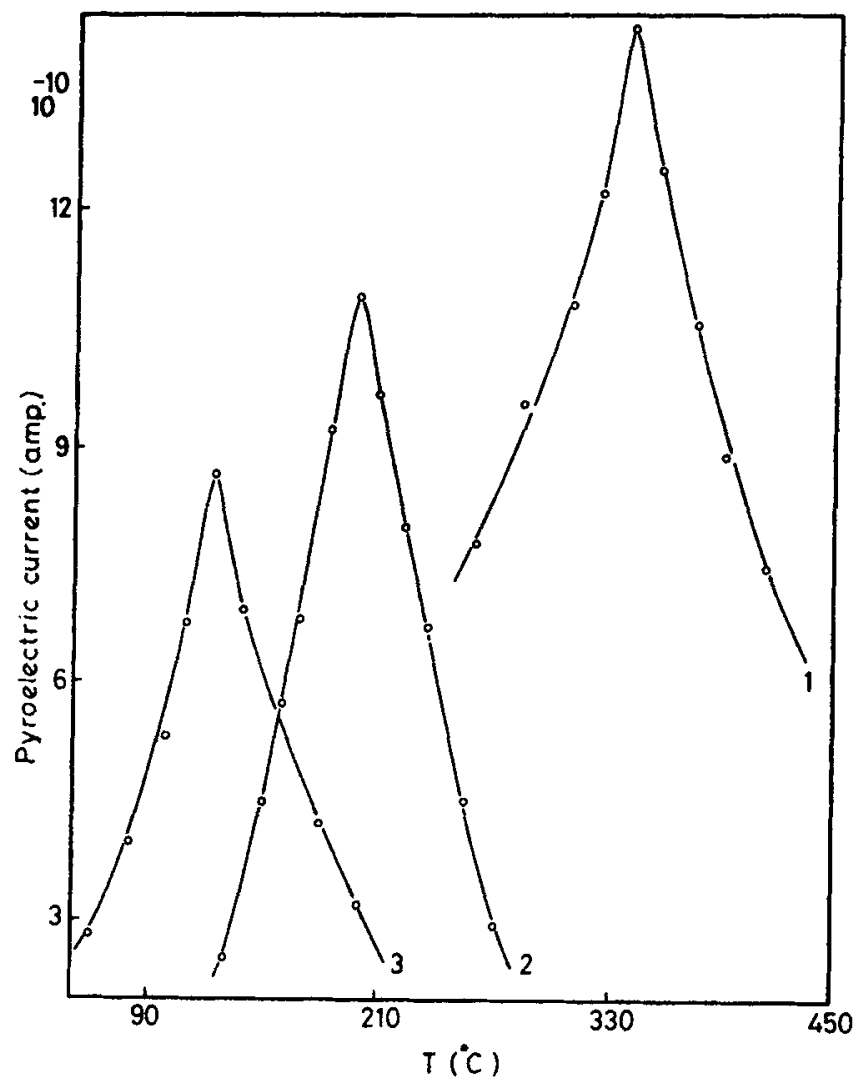

Figure 2. Temperature dependence of the pyroelectric current in poled sample 1. $\left(\mathrm{Pb}_{0.8}-\mathrm{Sr}_{0.2}\right) \mathrm{TiO}_{3}$, 2. $\left(\mathrm{Pb}_{0.6}-\mathrm{Sr}_{0.4}\right) \mathrm{TiO}_{3}$, and 3. $\left(\mathrm{Pb}_{0.5}-\mathrm{Sr}_{0.5}\right) \mathrm{TiO}_{3}$.

Table 1. Values of various parameters for different $\mathrm{PbTiO}_{3}, \mathrm{BaTiO}_{3}$ and $\mathrm{SrTiO}_{3}$ solid solutions.

\begin{tabular}{lccc}
\hline Substance & $\begin{array}{c}\text { Pyroelectric } \\
\text { current } \\
10^{-10} \mathrm{~A} / \mathrm{cm}^{2}\end{array}$ & $\begin{array}{c}\text { Pyroelectric } \\
\text { coefficient } \\
10^{-9} \mathrm{C} / \mathrm{cm}^{2} /{ }^{\circ} \mathrm{C}\end{array}$ & $\begin{array}{c}\text { Curie } \\
\text { temp. } \\
\left({ }^{\circ} \mathrm{C}\right)\end{array}$ \\
\hline$\left(\mathrm{Pb}_{0.8}-\mathrm{Ba}_{0.2}\right) \mathrm{TiO}_{3}$ & 24.3 & 58.3 & 440 \\
$\left(\mathrm{~Pb}_{0.6}-\mathrm{Ba}_{0.4}\right) \mathrm{TiO}_{3}$ & 18.8 & 28.2 & 380 \\
$\left(\mathrm{~Pb}_{0.5}-\mathrm{Ba}_{0.5}\right) \mathrm{TiO}_{3}$ & 13.3 & 24.0 & 350 \\
$\left(\mathrm{~Pb}_{0.8}-\mathrm{Sr}_{0.2}\right) \mathrm{TiO}_{3}$ & 14.2 & 37.0 & 340 \\
$\left(\mathrm{~Pb}_{0.6}-\mathrm{Sr}_{0.4}\right) \mathrm{TiO}_{3}$ & $10 \cdot 8$ & $19 \cdot 5$ & 200 \\
$\left(\mathrm{~Pb}_{0.5}-\mathrm{Sr}_{\mathbf{0} .5}\right) \mathrm{TiO}_{3}$ & 8.6 & 17.9 & 125 \\
\hline
\end{tabular}

\section{References}

Byer R L and Roundy C B 1972 Ferroelectrics 3333

Cady W G 1946 Piezoelectricity (New York: McGraw-Hill)

Chynoweth A G 1956 J. Appl. Phys. 2778

Imai K, Kawada S and Ida M 1966 J. Phys. Soc. Jpn 211855

Lang S B, Rice L H and Shaw S A 1969 J. Appl. Phys. 404335 
Mansingh A and Sreenivas K 1983 Ferroelectr. Lett. Sec. 167

Mathur S C, Baira A Y and Singh H 1981 Ferroelectrics 391197

Pearls T A, Diesel T J and Dobrov W I 1958 Appl. Phys. 291297

Sawada S and Nomura S 1950 Rep. Insı. Sci. Tech. Tokyo Univ. 4217

Sawada S, Nomura S and Asao Y 1961 J. Phys. Soc. Jpn. 162486

Srinivasan M R 1984 Bull. Mater. Sci. 6317

Tawfik A 1969 M.Sc. Thesis, Physics Department, Faculty of Science, Cairo University

Tawfik A 1974 Indian J. Phys. 48294

Vasileva L D 1977 Vestn Kiev Politekhn. In. Ta Ser Radio electron 1418

Yuhan Xu 1984 Ferroelectr. Lett. Sec. 2189 